\title{
Thermal Properties of Copper Matrix-Ceramic Filler Composite Prepared by Polymer Solution Method
}

\author{
Bok-Hyun Oh${ }^{1}$, Chung-Il Ma', Ji-Yeon Kwak ${ }^{2}$, Heon Kong ${ }^{3}$, and Sang-Jin Lee ${ }^{1,3 *}$ \\ ${ }^{1}$ Department of Advanced Materials Science and Engineering, Mokpo National University, Muan 58554, Republic of Korea \\ ${ }^{2}$ Department of Physiology and Biophysics, Inha University Colleage of Medicine, Incheon 22212, Republic of Korea \\ ${ }^{3}$ Research Institute of Ceramic Industry and Technology, Mokpo National University, Muan 58554, Republic of Korea
}

\begin{abstract}
A copper $(\mathrm{Cu})$ metal-ceramic filler composite with high thermal conductivity and a suitable thermal expansion coefficient was designed for application as a high-performance heat dissipation material. The purpose of the designed material was to utilize the high thermal conductivity of $\mathrm{Cu}$ while lowering its high coefficient of thermal expansion by using a ceramic filler. In this study, a $\mathrm{Cu}$-sol containing a certain amount of $\mathrm{AlN}$ or $\mathrm{SiC}$ ceramic filler was prepared using a non-aqueous solvent. A complex was produced by applying a PVB polymer to prepare a homogeneous precursor. The composite sintered without pressure in a reducing atmosphere showed low thermal conductivity due to residual pores, but the hot press sintered composite exhibited improved thermal conductivity. The Cu composite with $30 \mathrm{wt} \%$ AlN filler added exhibited a thermal conductivity of $290 \mathrm{~W} / \mathrm{m} \cdot \mathrm{K}$ and a thermal expansion coefficient of $9.2 \times 10^{-6} /{ }^{\circ} \mathrm{C}$. Due to the pores in the composite, the thermal conductivity showed some difference from the theoretical value calculated from the rule of mixture. However, the thermal expansion coefficient did not show any significant difference.
\end{abstract}

(Received June 11, 2021; Accepted September 27, 2021)

Keywords: metal-ceramic composite, thermal conductivity, thermal expansion coefficient, polymer solution method, hot press sintering

\section{Introduction}

The amount of heat generated by electronic devices increases as the performance and integration of the electric and electronic devices continues to increase. Furthermore, the heat generated in the material causes the deterioration of functions and malfunctions in peripheral devices and degrades the durability of equipment. For these reasons, a great deal of research has been conducted on technology to control the generated heat [1-5]. In general, the heat generated from an electronic device is controlled using a heat sink. The heat dissipation material used for this purpose has high thermal conductivity and a thermal expansion coefficient suitable for electronic devices such as semiconductors and LEDs. In the case of a heat dissipation material made of a single metal, there is an advantage of having excellent

\footnotetext{
- 오복현: 석사과정, 마충일 · 공헌: 연구원, 곽지연 · 이상진: 교수

*Corresponding Author: Sang-Jin Lee

[Tel: +82-61-450-2493, E-mail: lee@mokpo.ac.kr]

Copyright (c) The Korean Institute of Metals and Materials
}

thermal conductivity. However, failures may be caused by residual stresses due to differences in the coefficient of thermal expansion from electronic components such as a semiconductor substrate, because the single metal has a relatively high coefficient of thermal expansion. In order to solve this problem, studies have been actively conducted on the metal base-ceramic filler composite materials manufactured using a metal having high thermal conductivity as a matrix and a ceramic having low thermal expansion coefficient as a filler [6-8]. To manufacture such composite materials, a mechanical mixing method using solid powder is applied [912]. For example, according to a study by J. Tian [9], a CuAlN composite having a thermal conductivity of $235 \mathrm{~W} / \mathrm{m} \cdot \mathrm{K}$ and a thermal expansion coefficient of $12.6 \times 10^{-6} /{ }^{\circ} \mathrm{C}$ was fabricated by mixing AIN of $40 \mathrm{vol} \%$ (including $6 \mathrm{wt} \%$ $\mathrm{Y}_{2} \mathrm{O}_{3}$ ) with $\mathrm{Cu}$ and sintering by a hot pressing method. According to another study [10], when manufacturing a mechanical alloy of $\mathrm{Cu}-\mathrm{AlN}$ by attrition milling, the behavior of the thermal expansion coefficient that approaches Turner's rule was investigated. Here, when the content of $\mathrm{Cu}$ exceeded 
$60 \mathrm{vol} \%$, it was found that the theoretical rule of the mixture was almost identical to the calculated value. In this study, a thermal conductivity of less than $100 \mathrm{~W} / \mathrm{m} \cdot \mathrm{K}$ was observed due to pores in the $\mathrm{Cu}$ matrix. These methods have the disadvantage of not satisfying the thermal properties, especially thermal conductivity, due to the difficulty of homogeneous mixing and the presence of pores with local aggregation and a heterogeneous microstructure. To solve these problems, it is necessary to apply liquid base mixing and sintering processes to enhance the densification of the composite.

In the present study, $\mathrm{Cu}$ which has excellent thermal conductivity among metal materials was used as the basematrix material, and $\mathrm{AIN}$ and $\mathrm{SiC}$ which have relatively high thermal conductivity and low thermal expansion coefficient, were selected as the filler materials to make the metalceramic composite. The composite was designed to maintain high thermal conductivity and to reduce the thermal expansion coefficient of the $\mathrm{Cu}$ matrix for application as a high performance heat dissipation material. A new method was employed, in which a ceramic powder filler and a $\mathrm{Cu}$ sol were mixed to form a slurry-type precursor. In particular, a polymer solution method was applied for a homogeneous $\mathrm{Cu}$ sol. The polymer solution synthesis method is one of the solgel methods. This is a powder synthesis method in which the physical action of steric entrapment between cations dissolved in a solvent and polyvinyl alcohol causes dispersion of the cations to obtain precursors that are chemically homogeneous and stable [11-15]. This process has the advantage that the particle size of the produced powder can be controlled to prepare a very fine powder through an appropriate milling process, and thus the powder compact has excellent sintering properties [16-18]. In this study, the dried and calcined composite powders prepared by the solid-liquid hybrid method employing the polymer solution method were hot pressed to obtain a dense metal matrix-ceramic filler composite. The microstructure and thermal properties of the composite were also examined.

\section{Experimental Procedure}

Cupric nitrate hydrate $\left(\mathrm{Cu}\left(\mathrm{NO}_{3}\right)_{2} \cdot 2.5 \mathrm{H}_{2} \mathrm{O}, 98 \%\right.$ purity, Sigma-Aldrich, Co., USA) was used as a precursor for $\mathrm{Cu}$ as the matrix material. AlN powder (99\% purity, $\mathrm{H}$ type, Tokuyama, Japan) and SiC powder (\#10000, 99\% purity, Dongkwang Micron Co., Ltd., Korea) were used for the ceramic powder added as a filler. The microstructure of each powder is shown in Fig. 1. It is shown that AIN has a spherical particle size of $0.2 \mu \mathrm{m}$, and the $\mathrm{SiC}$ has a wide particle size distribution from $0.1 \sim 0.5 \mu \mathrm{m}$.

The cupric nitrate hydrate powder was dissolved in ethyl acetate (99\%, Daejung Chemicals \& Metals Co., Ltd., Korea), and the solid AlN or SiC powders were added to the mass ratio contents of the base matrix and filler, respectively. In order to maximize the dispersion of the ceramic filler, PVB (polyvinyl butyral, Sigma-Aldrich, molecular weight : $50,000 \sim 80,000$ ) was mixed by adding $5 \mathrm{wt} \%$ solution in a mass ratio. The slurry was dried while stirring on a hot plate, and then the obtained gel-type precursor was completely dried in a dry oven for 24 hours. As AIN decomposes upon reaction with water, the ethyl acetate was used as a solvent in this study.

The completely dried precursors were calcined in a reducing atmosphere $(4 \% \mathrm{H} 2$ - $\mathrm{Ar}$ gas $)$ at $500{ }^{\circ} \mathrm{C}$, for 1 hour at a heating rate of $3{ }^{\circ} \mathrm{C}$ per minute to remove organic materials. The flow rate of the gas was set at $70 \mathrm{NmL} / \mathrm{min}$ in consideration of the chamber size $(500 \mathrm{cc})$ of the tube

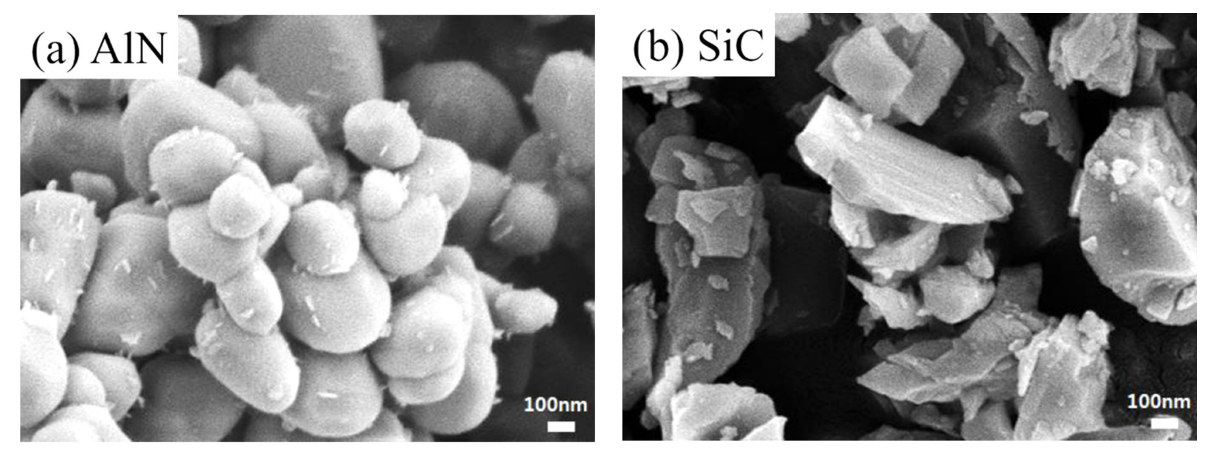

Fig. 1. FE-SEM micrographs of ceramic filler materials. (a) AIN, (b) SiC 
furnace. The calcined powders were uniaxially pressed at 10 $\mathrm{MPa}$, and then sintered at $990{ }^{\circ} \mathrm{C}$ for 1 hour under a reducing atmosphere $\left(4 \% \mathrm{H}_{2}-\mathrm{Ar}\right.$ gas $)$ at a heating rate of $3{ }^{\circ} \mathrm{C}$ per minute. In addition, hot pressing was performed to obtain a more densified sintered body. Finally, pressure sintering was conducted with the sample previously sintered (without pressure), at $900{ }^{\circ} \mathrm{C}$ for 1 hour under a reducing atmosphere and a pressure of $20 \mathrm{MPa}$.

In order to examine the crystallization behavior of the prepared precursor, an X-ray diffractometer (XRD, X'pertpro MPD, PAN analytical, Netherlands) was used. The analysis was conducted using a $\mathrm{Cu}-\mathrm{K} \alpha$ characteristic wavelength with a scan speed of $4 \% \mathrm{~min}$. The microstructures of the synthesized precursor and the metal base composition were observed using a field emission scanning electron microscope (FESEM: JSM-7100F. JEOL, Japan). The sample was fixed using a carbon tape in an aluminum holder and coated with Au-Pd via sputtering to observe the microstructure. In order to measure the thermal conductivity of the composite, a laser flash apparatus (LFA: LFA447 Nanoflash. NETZSCH, Germany) with a laser flash was used. The specimen was heated by laser at a heating rate of $10^{\circ} \mathrm{C}$ per minute from room temperature to $300{ }^{\circ} \mathrm{C}$, and the time it took for heat to be transferred to the opposite side was measured with an infrared sensor. The thermal expansion coefficient of the composite was examined using a thermo mechanical analyzer (TMA: TMA402F1 Hyperion. NETZSCH, Germany), and was measured from room temperature to $600 \mathrm{C}$. The relative density of the composites was calculated based on the theoretical density $\left(5.88 \mathrm{~g} / \mathrm{cm}^{3}\right.$ and $5.78 \mathrm{~g} / \mathrm{cm}^{3}$ of $\mathrm{Cu}-30 \%$ $\mathrm{AIN}$ and $\mathrm{Cu}-30 \% \mathrm{SiC}$ filler) obtained from the rule of mixture.
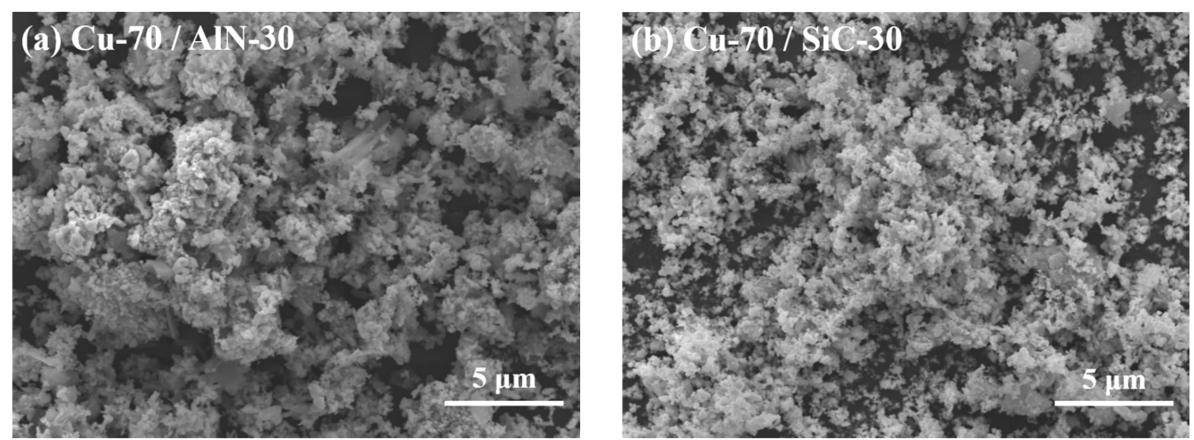

Fig. 2. FE-SEM micrographs of $\mathrm{Cu}$-ceramic filler composite powders calcined at $500{ }^{\circ} \mathrm{C}$. (a) $\mathrm{Cu} / 70: \mathrm{AlN} / 30$ (wt $\%$ ), (b) $\mathrm{Cu} / 70: \mathrm{SiC} / 30$ $(\mathrm{wt} \%)$.

\section{Results and Discussion}

Fig. 2 shows the microstructure of the composite powder obtained after calcination of the $\mathrm{Cu}-\mathrm{AlN}$ and $\mathrm{Cu}-\mathrm{SiC}$ precursor powders in a reducing atmosphere. The ceramic filler powder and the fine metal $\mathrm{Cu}$ powder were mixed without relatively large agglomeration. It was observed that after all of the PVB binder was degassed the microstructure showed a porous structure, and very fine $\mathrm{Cu}$ particles were partially aggregated around the filler powder. According to a previous study by S. J. Lee $[19,20]$, ultrafine $\mathrm{Cu}$ powder with a primary particle size of $10 \mathrm{~nm}$ was synthesized at $300{ }^{\circ} \mathrm{C}$ through the PVA polymer solution method. This study speculated that $\mathrm{Cu}$ powder close to a nano scale was synthesized by the polymer solution method.

Fig. 3 shows the results of an X-ray diffraction analysis of each sample after sintering the $\mathrm{Cu}-\mathrm{AlN}$ and $\mathrm{Cu}-\mathrm{SiC}$ composite powders prepared using the PVB polymer solution synthesis method. No second phase by the reaction between the $\mathrm{Cu}$ and the ceramic filler was observed, and only the peaks of the $\mathrm{Cu}$ and the ceramic filler were observed. Although the presence of reactants that can affect the thermal conductivity is excluded, the effect of pores in the sintered body and defects in the lattice will be important considerations for thermal conductivity and thermal expansion coefficient. According to a study by G. A. Slack [21], in the case of AlN, when exposed to oxygen in the atmohere, $\mathrm{Al}_{2} \mathrm{O}_{3}$ is formed on the surface of the AIN particles, and upon sintering, oxygen is introduced into the AIN lattice to form aluminum voids. In ceramics these vacancies scatter thermal energy via the heat transfer mechanism of phonon conduction and cause a decrease in thermal conductivity. It is therefore important to 

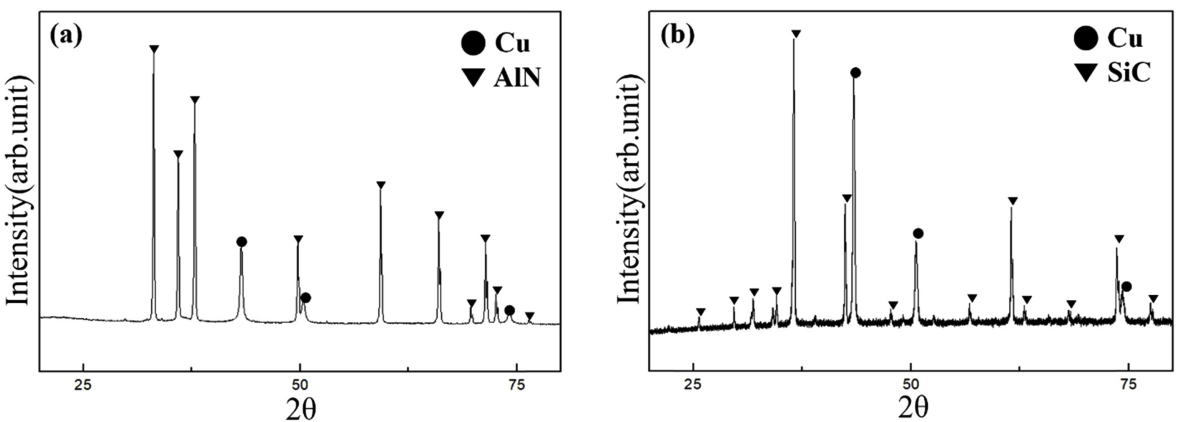

Fig. 3. XRD results of (a) $\mathrm{Cu} / 70$ : $\mathrm{AlN} / 30$ (wt $\%$ ) and (b) $\mathrm{Cu} / 70: \mathrm{SiC} / 30$ (wt $\%$ ) sintered composites.
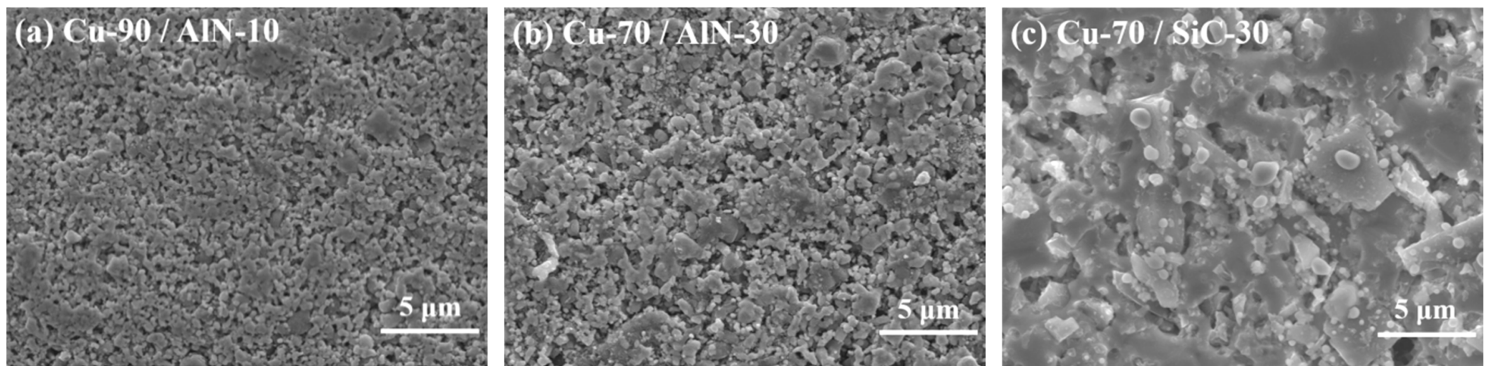

Fig. 4. FE-SEM micrographs of pressureless sintered $\mathrm{Cu}$ matrix composites with $\mathrm{AlN}$ or $\mathrm{SiC}$ fillers. (a) $\mathrm{Cu} / / 90$ : $\mathrm{AlN} / 10$ (wt $\%$ ), (b) $\mathrm{Cu} / 70$ : $\mathrm{AlN} / 30(\mathrm{wt} \%),(\mathrm{c}) \mathrm{Cu} / 70: \mathrm{SiC} / 30(\mathrm{wt} \%)$.

remove oxygen from the lattice. In this experiment, when calcination and sintering were performed to manufacture the composite, the atmosphere was controlled by using highpurity reducing gases to prevent reactions with oxygen in the atmosphere.

Fig. 4 shows the surface microstructure of the pressureless sintered body of $\mathrm{Cu}-\mathrm{AlN}$ and $\mathrm{Cu}-\mathrm{SiC}$ composite powders. It was found that as the amount of AIN filler increased, the densification of $\mathrm{Cu}$ interfered with the increase in pores in the sintered body. When $30 \mathrm{wt} \%$ of $\mathrm{SiC}$ was added as a filler, the densification of the $\mathrm{Cu}$ matrix improved more than that observed with the use of AlN, but pores in were still observed the sintered body. Since the pores in the manufactured composite material significantly influence thermal conductivity, it is important to minimize them as much as possible.

Hot press sintering was performed to reduce the pores in the composite. Fig. 5 shows the surface microstructure of the specimen after hot press sintering by adding $30 \mathrm{wt} \%$ of AlN or $\mathrm{SiC}$ filler to the $\mathrm{Cu}$ matrix. Compared to the composite
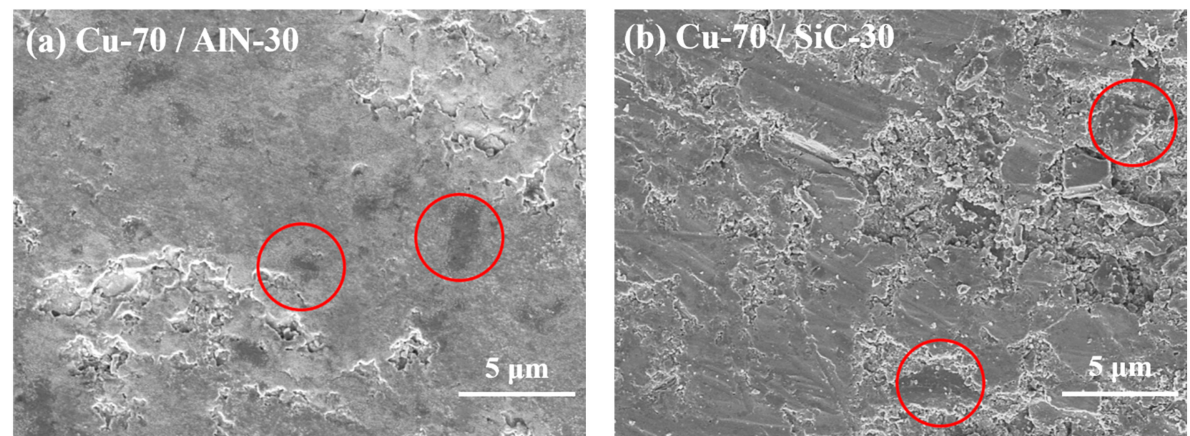

Fig. 5. FE-SEM micrographs of hot press sintered $\mathrm{Cu}$ matrix composites with $\mathrm{AlN}$ or $\mathrm{SiC}$ filler. (a) $\mathrm{Cu} / 70: \mathrm{AlN} / 30$ (wt $\%$ ), (b) $\mathrm{Cu} / 70: \mathrm{SiC} /$ $30(\mathrm{wt} \%)$ 

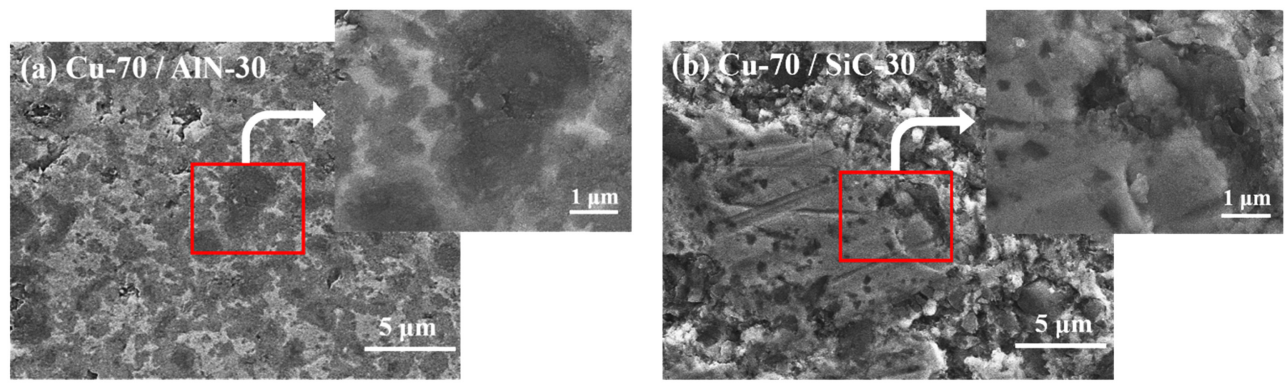

Fig. 6. FE-SEM micrographs of interface between copper matrix with ceramic filler. (a) $\mathrm{Cu} / 70: \mathrm{AlN} / 30$ (wt\%), (b) $\mathrm{Cu} / 70$ : $\mathrm{SiC} / 30$ (wt\%).

prepared by pressureless sintering, the pores were notably reduced, and hence a relatively dense $\mathrm{Cu}$ composite microstructure was observed. The measured densities of the hot-pressed $\mathrm{Cu}-30 \% \mathrm{AlN}$ and $\mathrm{Cu}-30 \% \mathrm{SiC}$ composite were $5.67 \mathrm{~g} / \mathrm{cm}^{3}$ (96.4\% relative density) and $5.51 \mathrm{~g} / \mathrm{cm}^{3}(95.3 \%$ relative density), respectively. The shape of the ceramic filler was clearly observed and a few filler particles were agglomerated (circle marks). According to previous experiments [22], such a compact structure could not be obtained by hot press sintering when using a commercial $\mathrm{Cu}$ powder, which has a larger and non-uniform particle size compared with the fine $\mathrm{Cu}$ powder synthesized in the liquid phase. More specifically, in the composite with the ceramic filler, since the densification of the $\mathrm{Cu}$ matrix is hindered by the influence of the filler, the second phase might be a critical variable for densification.

Fig. 6 shows an enlarged image of the microstructure at the interface between the $\mathrm{Cu}$ matrix and the ceramic filler. It was confirmed that the interface between the $\mathrm{Cu}$ matrix and the filler is tightly bonded without reactants. Most of the pores were observed in the area where the ceramic filler had agglomerated. While the AIN has spherical-shaped particles with a narrower particle size distribution, while $\mathrm{SiC}$ had angular-shaped particles with a $0.1 \sim 0.5 \mu \mathrm{m}$ wide particle size distribution. The $\mathrm{SiC}$ particles were aggregated or heterogeneously mixed with $\mathrm{Cu}$ powder around the sharpened polygonal particles, and some pores were generated. Fig. 7 shows the results of the EDS mapping analysis of the pressure sintered composites. It can be seen that the ceramic fillers show a homogeneous distribution over a wide range of microstructure without large aggregation.

Fig. 8 shows the thermal conductivity of the $\mathrm{Cu}-\mathrm{AlN}$ composites and the monolithic copper plate. The measured thermal conductivity of the $\mathrm{Cu}$ plate sample at $50^{\circ} \mathrm{C}$ was $447 \mathrm{~W} / \mathrm{m} \cdot \mathrm{K}$. The thermal conductivity of the composite containing $10 \mathrm{wt} \%$ of AlN filler prepared by sintering at atmospheric pressure was $134 \mathrm{~W} / \mathrm{m} \cdot \mathrm{K}$. In case of $30 \mathrm{wt} \%$ of AlN sample sintered at atmospheric pressure showed a thermal conductivity of $172 \mathrm{~W} / \mathrm{m} \cdot \mathrm{K}$. The low thermal conductivity is ascribed to the many pores present after atmospheric pressure sintering, as shown in the microstructure image in Fig. 4(a) and 4(b).

Assuming there were no pores in the $\mathrm{Cu}-\mathrm{AlN}$ composite, the theoretical thermal conductivity can be calculated using the rule of mixture.

$$
\alpha_{e}=\alpha_{m} V_{m}+\alpha_{f} V_{f}
$$
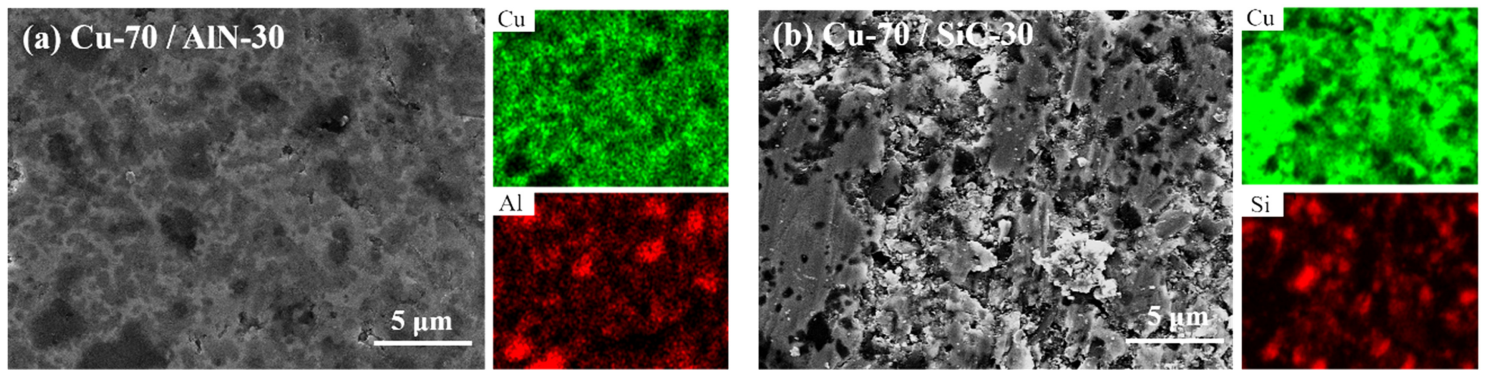

Fig. 7. EDS mapping results of hot press sintered $\mathrm{Cu}$ matrix composites with $\mathrm{AIN}$ or $\mathrm{SiC}$ filler. (a) $\mathrm{Cu} / 70: \mathrm{AlN} / 30$ (wt $\%$ ), (b) $\mathrm{Cu} / 70: \mathrm{SiC} /$ $30(\mathrm{wt} \%)$. 


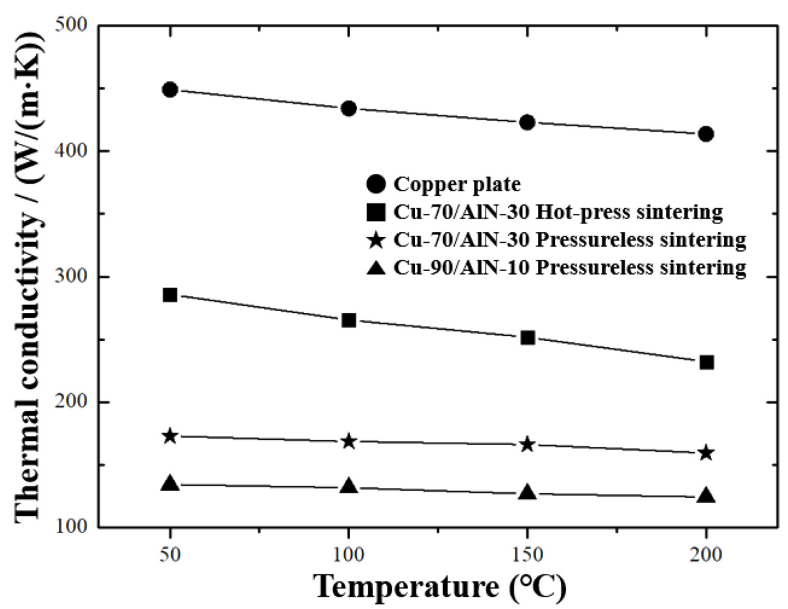

Fig. 8. Measured thermal conductivity of sintered $\mathrm{Cu}-\mathrm{AlN}$ composites.

Here, $\alpha_{e}$ is the calculated thermal conductivity of the composite, $\alpha_{m}$ is the thermal conductivity of the single phase $\mathrm{Cu}$, about $400 \mathrm{~W} / \mathrm{m} \cdot \mathrm{K}, \mathrm{V}_{m}$ is the volume fraction of $\mathrm{Cu}, \alpha_{f}$ is the thermal conductivity of AlN used as filler, about $280 \mathrm{~W} /$ $\mathrm{m} \cdot \mathrm{K}$, and $\mathrm{V}_{f}$ is the volume fraction of AIN. The calculated thermal conductivity for the composite with $10 \mathrm{wt} \% \mathrm{AIN}$ filler was $360 \mathrm{~W} / \mathrm{m} \cdot \mathrm{K}$. The difference between the measured and calculated values is attributed to the presence of pores in the sintered body and the lattice diffusion of oxygen impurities during the sintering process. A. L. Loeb [23] reported that materials with good thermal conductivity displayed rapid heat transfer in one direction, however if pores were present, the heat flow was cut off or flowed in the other direction, adversely affecting thermal conductivity. In case of the hot-pressed sample, which exhibited a denser microstructure (Fig. 5(a)), the measured thermal conductivity was improved $\left(290 \mathrm{~W} / \mathrm{m} \cdot \mathrm{K}\right.$ at at $\left.50{ }^{\circ} \mathrm{C}\right)$ even though the AIN filler content was increased to $30 \mathrm{wt} \%$. This means that the amount of pores has a greater effect on thermal conductivity than the filler content.

Fig. 9 shows the measured thermal conductivity of the atmospheric pressure sintered $\mathrm{Cu} / \mathrm{SiC}$ composites. Assuming a fully densified $\mathrm{Cu}$ and $\mathrm{SiC}$ composite that excludes the presence of pores, the thermal conductivity of the composite according to the mixing ratio of $\mathrm{SiC}$ was calculated using the rule of mixture. The thermal conductivity was calculated as $382 \mathrm{~W} / \mathrm{m} \cdot \mathrm{K}$ at $10 \mathrm{wt} \% \mathrm{SiC}$ filler, $356 \mathrm{~W} / \mathrm{m} \cdot \mathrm{K}$ at $15 \mathrm{wt} \% \mathrm{SiC}$ filler, and $333 \mathrm{~W} / \mathrm{m} \cdot \mathrm{K}$ at $20 \mathrm{wt} \% \mathrm{SiC}$ filler. There was a

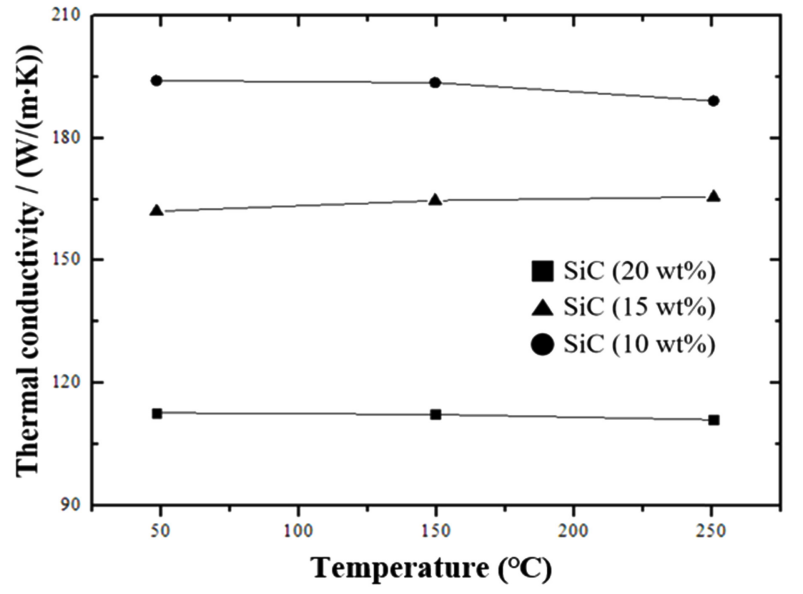

Fig. 9. Measured thermal conductivity of pressureless sintered $\mathrm{Cu}-$ $\mathrm{SiC}$ composites.

significant difference between the calculated thermal conductivity and the actual measured value. It is considered that this difference is also caused by a large number of pores resulting from less densification of the $\mathrm{Cu}$ composite as the amount of $\mathrm{SiC}$ filler content increase.

Fig. 10 shows the thermal expansion behavior of the pure $\mathrm{Cu}$ plate and $\mathrm{Cu} /$ ceramic composites. Furthermore, Table 1 shows the thermal expansion coefficient at $200{ }^{\circ} \mathrm{C}$ calculated by the rule of mixture and the average value of the thermal expansion coefficient between $200{ }^{\circ} \mathrm{C} \sim 600^{\circ} \mathrm{C}$ calculated based on actual graph of the thermal expansion behavior. The thermal expansion coefficient of the pure $\mathrm{Cu}$ plate calculated from the graph was $16.3 \times 10^{-6} /{ }^{\circ} \mathrm{C}$, but it decreased to

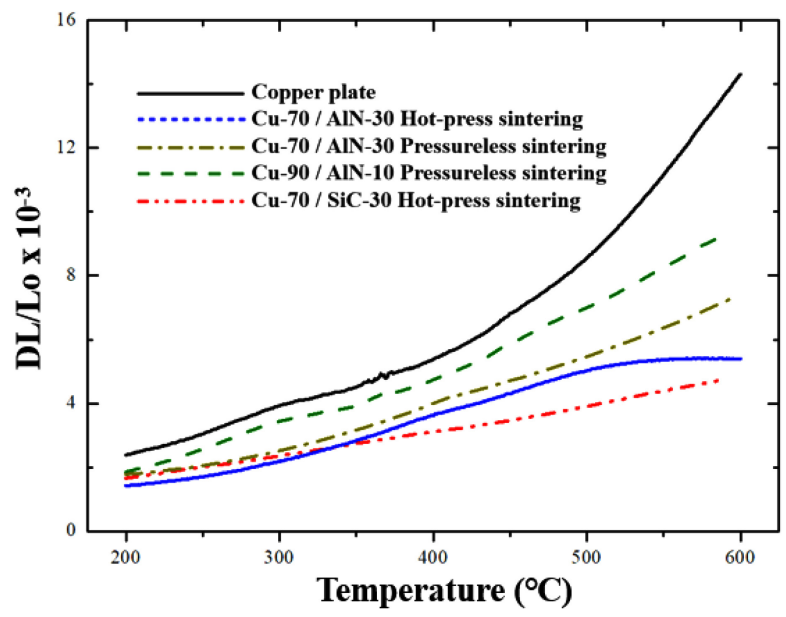

Fig. 10. Measured thermal expansion of sintered $\mathrm{Cu}$ composites with $\mathrm{SiC}$ and $\mathrm{AIN}$ fillers. 
Table 1. Comparison of Thermal Expansion Coefficient of Sintered $\mathrm{Cu}$ Composites with AIN or SiC Fillers.

\begin{tabular}{|c|c|c|}
\hline \multirow{2}{*}{ Material } & \multicolumn{2}{|c|}{$\begin{array}{l}\text { Thermal expansion coefficient }(\alpha) \\
\qquad\left(\times 10^{-6} /{ }^{\circ} \mathrm{C}\right)\end{array}$} \\
\hline & $\begin{array}{l}\alpha \text { obtained from } \\
\text { rule of mixture }\end{array}$ & $\begin{array}{l}\text { Average A from } \\
\text { Fig. } 10\end{array}$ \\
\hline Copper Plate & 16.50 & 16.30 \\
\hline $\begin{array}{l}\mathrm{Cu}-70 / \text { AlN-30 } \\
\text { Hot Press sintering }\end{array}$ & 9.79 & 9.20 \\
\hline $\begin{array}{l}\mathrm{Cu}-70 \text { / AlN-30 } \\
\text { Pressureless sintering }\end{array}$ & 9.79 & 9.69 \\
\hline $\begin{array}{c}\mathrm{Cu}-70 \text { / SiC-30 } \\
\text { Hot Press sintering }\end{array}$ & 9.47 & 8.47 \\
\hline $\begin{array}{l}\mathrm{Cu}-90 \text { / AlN-10 } \\
\text { Pressureless sintering }\end{array}$ & 13.59 & 13.30 \\
\hline
\end{tabular}

$13.3 \times 10^{-6} /{ }^{\circ} \mathrm{C}$ when $10 \mathrm{wt} \%$ AlN filler was added. The thermal expansion coefficient decreased to $9.2 \times 10^{-6} /{ }^{\circ} \mathrm{C}$ when the AlN filler was increased to $30 \mathrm{wt} \%$ and the composite was subjected to pressure sintering. The thermal expansion coefficient of the composite tended to decrease as the ceramic filler content increased, when adding a ceramic filler with a low thermal expansion coefficient. Furthermore, there was no significant difference between the thermal expansion coefficient calculated using the rule of mixture and the measured average thermal expansion coefficient [10]. In the composite, the thermal expansion coefficient is affected by various factors such as adhesion at the interface, dispersion of the filler, filler shape etc. However, it was found that the presence of pores did not significantly affect the thermal expansion coefficient in contrast to the thermal conductivity.

\section{Conclusions}

A Cu matrix-ceramic filler composite, with a homogeneous microstructure, was fabricated using a polymer solution synthesis method, and the physical properties were examined with different ceramic filler content and sintering methods. As the filler content increased, the densification was hindered, and more pores were observed. These pores had a significant influence, lowering the thermal conductivity. A dense composite with reduced pores could be obtained by hot press sintering. The densified composite finally showed a thermal conductivity of $290 \mathrm{~W} / \mathrm{m} \cdot \mathrm{K}$ and a thermal expansion coefficient of $9.2 \times 10^{-6} /{ }^{\circ} \mathrm{C}$, when $30 \mathrm{wt} \%$ AlN filler was added.

By adding a suitable ceramic filler to $\mathrm{Cu}$ and densifying it, it was possible to manufacture a new heat dissipation material with a lowers thermal expansion coefficient without significantly reducing the excellent thermal conductivity of $\mathrm{Cu}$.

\section{REFERENCES}

1. W.-J. Cho, S.-H. Oh, and I.-J. Shon, Korean J. Met. Mater. 57, 310 (2019).

2. X. Li, T. A. Ring, and B.-S. Choi, Korean J. Met. Mater. 57, 529 (2019).

3. W. Zhou, D. Yu, C. Min, Y. Fu, and X. Guo, J. Appl. Polym. Sci. 112, 1695 (2009).

4. X. C. Tong, Advanced Materials for Thermal Management of Electronic Packaging, 1437, Springer, Switzerland (2011).

5. A. Miranda, N. Barekar, and B. J. Mckay, J. Alloys Compd. 774, 820(2019).

6. M. Schobel, G. Requena, H. Kaminski, and H. P. Degischer, Mater. Sci. Forum, 571, 413 (2008).

7. X. H. He, X. H. Qu, and C. C. Jia, Sci. China, Ser. E: Technol. Sci. 52, 238 (2009).

8. S. B. Ren, X. B. He, and X. H. Qu, Compos. Sci. Technol. 67, 2103 (2007).

9. J. Tian and K. Shobu, J. Mater. Sci. 39, 1309 (2004).

10. K. M. Lee, T. Weissgarber, and B. Kieback, J. Mater. Sci. 39, 5235 (2004).

11. K. M. Lee, D. K. Oh, W. S. Choi, T. Weissgarber, and B. Kieback, J. Alloy. Compd. 434, 375 (2007).

12. M. R. Akbarpour, E. Salahi, F. A. Hesari, H. S. Kim, and A. Simchi, Mater. Des. 52, 881 (2013).

13. M. Zarei, M. B. Zarandi, and M. Alizadeh, Ceram. Int. 45, 1991 (2019).

14. T. Zaki, K. I. Kabel, and H. Hassan, Ceram. Int. 38, 4861 (2012).

15. D. R. Souza, J. V. S. Neves, Y. K. S. Franca, and W. C. Malheiro, Photochem. Photobiol. 97, 32 (2021).

16. B. Liu, Y. You, H. Zhang, H. Wu, J. Jin, and H. Liu, RSC. Adv. 6, 110349 (2016).

17. H. H. Im and S. J. Lee, Korean J. Mater. Res. 30, 573 (2020).

18. S. J. Lee and J. C. Hwan, J. Nanosci. Nanotechnol. 12, 800 
(2012).

19. S. J. Lee and Y. M. Han, J. Korean Inst. Met. Mater. 52, 335 (2014).

20. Y. M. Han, C. H. Jung, and S. J. Lee, J. Nanosci. Nanotechnol. 15, 5475 (2015).
21. G. A. Slack, J. Phys. Chem. Solids. 34, 321 (1973).

22. B. H. Oh, C. I. Ma, and S. J. Lee, Kor. J. Mater. Res. 302, 93 (2020).

23. A. L. Loeb, J. Am. Ceram. Soc. 37, 96 (1954). 